\title{
Bedtime insulin injections: an alternative regimen
}

\author{
F R J HINDE AND D I JOHNSTON
}

Children's Department, University Hospital, Queen's Medical Centre, Nottingham

SUMMARY Sixteen children (aged 3 to 12 years) participated in a 12 month crossover study comparing bedtime with teatime insulin injections in an endeavour to reduce morning hyperglycaemia. Blood glucose values were lower at lunch and at teatime on the later injection, but higher at bedtime and midnight. There was no overall change in glycosylated haemoglobin. Despite more frequent mild hypoglycaemic attacks, parents preferred the convenience of the later injection. Analysis of individual children's glycosylated haemoglobin values showed that those whose metabolic control improved on the later injection were younger and went to bed earlier, indicating that this regimen may have a place in the management of younger children with diabetes mellitus.

In recent years the evidence relating glycaemic control to long term complications has increased, ${ }^{1}$ and the patient now considered 'well controlled' is one whose blood glucose and glycosylated haemoglobin values are as close to the physiological range as is compatible with an acceptably normal lifestyle. This goal is rarely attained in practice, and is particularly challenging for the paediatrician. ${ }^{2}$

One of the major barriers to improved glycaemic control on conventional once or twice daily insulin regimens is the so called 'dawn phenomenon' ${ }^{3}$ This consists of a rise in the blood glucose concentration starting in the early hours of the morning and continuing after breakfast, causing the midmorning blood glucose peak so frequently seen in insulin dependent patients. Initial experience with continuous subcutaneous insulin infusions suggested that this rise could be reduced by maintaining constant insulin values overnight, ${ }^{4}$ and it is common experience that twice daily insulin regimens fail to provide adequate insulin concentrations in the latter part of the night. A three injection study performed in adults, delaying the evening injection of intermediate acting insulin from the evening meal to bedtime, reduced the early morning glucose rise but failed to improve glycosylated haemoglobin values. ${ }^{5}$

Children are less likely to tolerate multiple injections than adults, and the interval between their evening meal and bedtime is shorter. We have, therefore, studied the effects of delaying the second injection of insulin from before the evening meal to bedtime in a group of under 12 year old children in their normal home environment.

\section{Methods}

Patients. Nineteen prepubertal children were selected from the Nottingham Children's Diabetic Clinic (Table 1) on the grounds of age and duration of diabetes. All patients and parents consented to take part in the study, which had local ethical committee approval. These 'compliant' patients had glycosylated haemoglobin values slightly below our clinic mean $(11.4 \%)$. One patient withdrew during the 'run in' period and two further children were subsequently excluded when it became apparent that they could be optimally controlled on a single daily injection of insulin. Sixteen children completed the study; none had any other metabolically relevant disorder. The only child admitted to hospital during the trial had an exacerbation of his asthma; this did not seem to alter his diabetic control.

All children had normal creatinine, urea, and electrolyte concentrations. All had normal blood pressure with no evidence of microvascular complications. Postprandial C peptide concentrations were uniformly low.

At entry to the study all children were being treated with twice daily highly purified pork insulin, using a mixture of intermediate and short acting insulin in the morning and intermediate (with or without short acting) before their evening meal (regimen A).

Procedure. After a four month run in period the children were randomised into two groups. One 
Table 1 Patient details at randomisation

\begin{tabular}{|c|c|c|c|c|c|c|}
\hline $\begin{array}{l}\text { Case } \\
\text { no }\end{array}$ & Sex & $\begin{array}{l}\text { Age } \\
\text { (years) }\end{array}$ & $\begin{array}{l}\text { Diabetes } \\
\text { duration } \\
\text { (years) }\end{array}$ & $\begin{array}{l}\text { Glycosylated } \\
\text { haemoglobin } \\
(\%)\end{array}$ & $\begin{array}{l}\text { Insulin dose } \\
\text { (U/kg/day) }\end{array}$ & $\begin{array}{l}\text { Postprandial } \\
\text { C peptide } \\
\text { (nmol/l) }\end{array}$ \\
\hline 2 & $\mathbf{M}$ & $10 \cdot 0$ & 3.9 & $12 \cdot 9$ & 0.72 & 0.08 \\
\hline 3 & $\mathbf{F}$ & $5 \cdot 0$ & $3 \cdot 6$ & $10 \cdot 6$ & $1 \cdot 00$ & 0.02 \\
\hline 4 & $\mathbf{M}$ & $9 \cdot 2$ & $3 \cdot 5$ & $9 \cdot 0$ & $1 \cdot 16$ & 0.02 \\
\hline 5 & $\mathbf{M}$ & $6 \cdot 5$ & $3 \cdot 2$ & 11.9 & 0.77 & 0.02 \\
\hline 6 & $\mathbf{M}$ & $3 \cdot 1$ & 1.8 & $10 \cdot 5$ & 0.75 & 0.02 \\
\hline 8 & $\mathbf{M}$ & $10 \cdot 9$ & $2 \cdot 4$ & $11 \cdot 3$ & 1.07 & $<0.01$ \\
\hline 9 & $\mathbf{M}$ & $6 \cdot 7$ & $4 \cdot 6$ & $8 \cdot 5$ & $0 \cdot 81$ & 0.02 \\
\hline 10 & $\mathbf{M}$ & $3 \cdot 8$ & $2 \cdot 4$ & $10 \cdot 9$ & 0.75 & 0.02 \\
\hline 11 & $\mathbf{M}$ & 4.4 & $2 \cdot 4$ & $6 \cdot 4$ & 0.79 & 0.02 \\
\hline 12 & $\mathbf{F}$ & $11 \cdot 6$ & $3 \cdot 6$ & 11.7 & $1 \cdot 26$ & $<0.01$ \\
\hline 15 & $\mathbf{F}$ & $10 \cdot 6$ & $2 \cdot 2$ & $12 \cdot 5$ & 0.75 & 0.02 \\
\hline 16 & $\mathbf{M}$ & $10 \cdot 8$ & 3.8 & $11 \cdot 4$ & 1.33 & 0.02 \\
\hline 17 & $\mathrm{~F}$ & $7 \cdot 5$ & 1.9 & $10 \cdot 4$ & 0.44 & 0.06 \\
\hline 18 & $\mathbf{M}$ & 8.0 & 4.7 & $10 \cdot 1$ & 1.00 & 0.02 \\
\hline Mean & & 7.9 & $3 \cdot 3$ & $10 \cdot 6$ & 0.89 & \\
\hline SD & & $2 \cdot 8$ & 1 & 1.7 & $0 \cdot 22$ & * \\
\hline Range & & $3 \cdot 1-11 \cdot 6$ & $1 \cdot 8-5 \cdot 5$ & $6.4-12.9$ & $0.44-1.33$ & \\
\hline
\end{tabular}

*Adult fasting reference range $(0 \cdot 18-0 \cdot 52 \mathrm{nmol} / \mathrm{l})$.

group received the standard regimen described above (regimen $\mathrm{A}$ ). The other group received a normal 'mixed' morning injection, no insulin before their evening meal, and an injection of intermediate acting insulin only given shortly before bedtime (regimen B). After four months the children were switched over to the alternative treatment regimen for the final four month treatment period.

Clinic visits coincided with randomisation and the completion of both study periods. Children were also visited at home at monthly intervals throughout the study. During the run in period efforts were made to optimise metabolic control, and in particular to achieve the lowest fasting blood glucose concentrations possible without producing nocturnal hypoglycaemia.

The total insulin dose was kept constant throughout both study periods by increasing the morning dose of intermediate acting insulin to compensate for the loss of the evening short acting insulin in regimen B. Parents were advised not to administer short acting insulin with the bedtime injection.

Monitoring. At each clinic attendance or home visit details of diabetic symptoms, hypoglycaemic episodes, insulin dose, and home blood glucose monitoring were obtained and a capillary blood sample taken for measurement of glycosylated haemoglobin.

The children were asked to provide a four point blood glucose series (three preprandial and one bedtime measurement) each week, as well as twice monthly midnight and 3 am measurements. All children used BM-Test-Glycemie 20-800 sticks (Boehringer-Mannheim) for their blood glucose monitoring. On the three mornings before each consultation fasting blood samples were collected into Sarstedt capillary tubes and stored in their domestic refrigerators until shortly before laboratory blood glucose analysis.

Height and weight were measured at each clinic visit and a two hour postprandial specimen of venous blood was obtained on one occasion for routine biochemistry and $C$ peptide assay.

Laboratory methods. Blood glucose was analysed with a glucose oxidase electrode (Yellow Springs Instruments). Blood for glycosylated haemoglobin analysis was taken into EDTA tubes, the cells were then washed in $0.85 \%$ saline, separated, and lysed in an acid haemolysing solution within two hours of sampling. The lysate was stored at $4^{\circ} \mathrm{C}$ until analysed by an electrophoretic method (Gelman Sciences). ${ }^{6}$ Each specimen was analysed twice with different membranes and the results presented are the average of the two readings. Blood for $\mathrm{C}$ peptide estimation was taken into Trasylol (Bayer), separated immediately, and the plasma stored at $-18^{\circ} \mathrm{C}$ until analysed by radioimmunoassay. ${ }^{7}$

Questionnaire. At the end of the study all parents completed a questionnaire comparing the effect of the two regimens on blood sugar control, problems with hypoglycaemia, and convenience and were asked to express their overall preference. All answers were on a 5 point scale: $3=$ no difference, 2 
and $4=$ one regimen better, 1 and $5=$ one regimen much better.

Statistical tests used are mentioned in the text.

\section{Results}

Blood glucose. Blood glucose profiles remained constant throughout the course of reach treatment regimen (Friedman two way analysis of variance). The values at individual time points, however, did not conform to a normal distribution. Results are therefore expressed as the median values of all children's median values for each time point. Quartile values are indicated in Fig. 1. P values shown are derived from Wilcoxon matched pairs signed ranks tests.

The two regimens produced different blood glucose profiles (Fig. 1). Home measured fasting blood glucose concentrations tended to be lower on regimen $\mathrm{B}$ than on regimen A $(6.6 v 8.6 \mathrm{mmol} / \mathrm{l}$; NS). The Sarstedt tube glucose concentrations showed a similar trend. At lunch time, blood glucose was significantly lower on regimen $B$ than on the regimen $\mathrm{A}(7.1 \vee 9.8 \mathrm{mmol} / \mathrm{l} ; \mathrm{P}<0.02)$, and this difference remained true at teatime $(9.1 \quad v \quad 10.2$ $\mathrm{mmol} / \mathrm{l} \mathrm{P}<0.004)$. By bedtime the direction of the difference had reversed and blood glucose concentrations were lower on regimen $\mathrm{A}$ than on regimen B $(10.4 v 12.3 \mathrm{mmol} / \mathrm{l} ; \mathrm{P}<0.001)$. This gap was less apparent by midnight $(9.8 v 11.5 \mathrm{mmol} / \mathrm{l} ; \mathrm{P}<0.03)$, and not statistically significant by 3 am $(7.7 v 9.0$ $\mathrm{mmol} / \mathrm{l}$; NS).

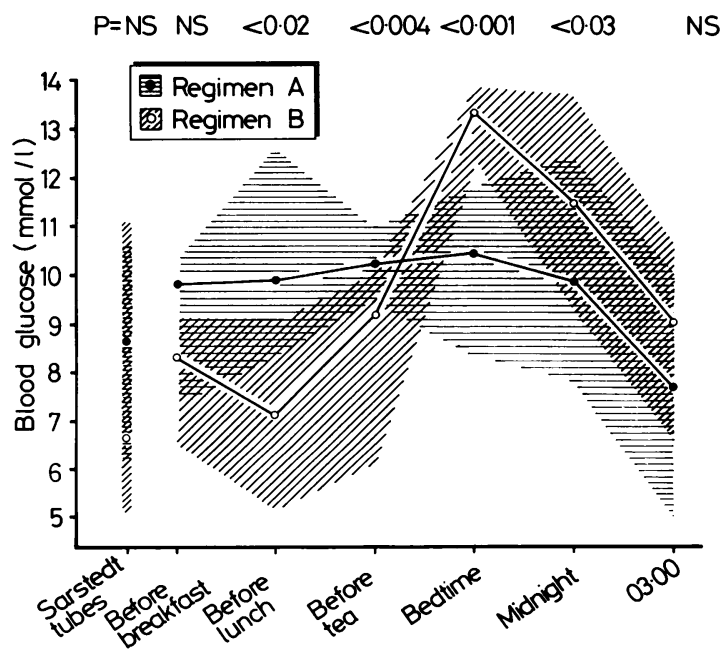

Fig. 1 Blood glucose profiles on regimens $A$ and $B$. $P$ values - Wilcoxon matched pairs sign rank test.
Table 2 Insulin dose and frequency of hypoglycaemic episodes on evening meal (regimen $A$ ) and bedtime (regimen B) injections (mean (SEM))

\begin{tabular}{|c|c|c|c|}
\hline & Regimen $A$ & Regimen $B$ & Significance ${ }^{*}$ \\
\hline $\begin{array}{l}\text { Total insulin dose } \\
\text { (U/kg/day) } \\
\% \text { Total insulin dose }\end{array}$ & $0.87(0.05)$ & $0.84(0.06)$ & NS \\
\hline taken as: & & & \\
\hline $\begin{array}{l}\text { Morning short acting } \\
\text { Morning intermediate }\end{array}$ & $18 \cdot 8(2 \cdot 3)$ & $16 \cdot 4(2 \cdot 4)$ & NS \\
\hline acting & $51.4(3.0)$ & $61 \cdot 1(2 \cdot 8)$ & $<0 \cdot 001$ \\
\hline $\begin{array}{l}\text { Evening short acting } \\
\text { Evening intermediate }\end{array}$ & $6 \cdot 1(1 \cdot 5)$ & 0 & \\
\hline acting & $23.7(1.7)$ & $22.6(1.5)$ & NS \\
\hline \multicolumn{4}{|l|}{$\begin{array}{l}\text { Hypoglycaemic attacks } \\
\text { (No/pt per } 4 \text { months) }\end{array}$} \\
\hline Mild & $5 \cdot 25(2.4)$ & $7.25(2.9)$ & $<0.04$ \\
\hline Moderate & $0.38(0 \cdot 16)$ & $0.81(0.38)$ & NS \\
\hline Severe & $0.13(0.09)$ & $0.25(0.11)$ & NS \\
\hline
\end{tabular}

*Student's paired $t$ test.

Hypoglycaemic episodes (see Table 2)

These were categorised as: mild=mild symptoms rapidly relieved; moderate $=$ made the child unwell, caused an upset to family routine; severe $=$ requiring glucagon, intravenous dextrose, or admission to hospital. There was a higher frequency of mild episodes on regimen $\mathrm{B}(\mathrm{P}<0.04)$, but no difference in the incidence of moderate or severe episodes.

\section{Anthropometry}

There was no significant difference in the height or weight velocity on the two treatment regimens.

\section{Glycosylated haemoglobin}

Because changes occurred within treatment periods, the figures analysed are the mean values from the last two months on each regimen. The mean glycosylated haemoglobin values on regimen B (9.88 (0.34) SEM) were not significantly different to those on regimen A $(9.61(0.23)$ SEM) (Student's paired $t$ test). Some children showed considerable changes on the two regimens, seven having lower values on regimen $B$ and nine on regimen $A$. Inspection of these results suggested that the younger children were more likely to improve on regimen B (Fig. 2). To assess the relative importance of age and other possible indicators of which children were likely to improve on regimen $B$, Spearman correlation coefficients were calculated between the change in glycosylated haemoglobin on the two regimens and other factors. No clear relation was established between changes in glycosylated haemoglobin and randomisation values of: duration of diabetes, fasting blood glucose, insulin dose per kilogram, and percentage of total daily insulin dose given as evening short acting insulin (Table 3 ). There were, how- 


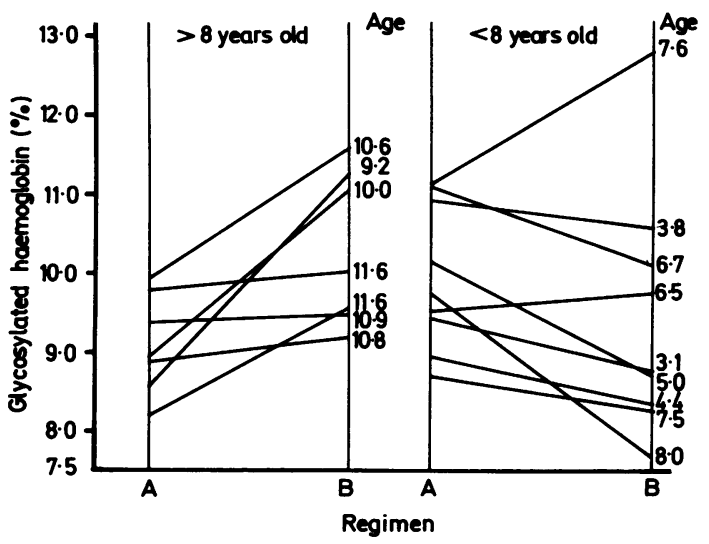

Fig. 2 Individual changes in glycosylated haemoglobin values on regimens $A$ and $B$.

Table 3 Correlations of change in glycosylated haemoglobin with patient details*

\begin{tabular}{|c|c|c|}
\hline & Spearmans ' $r s$ ' & Significance \\
\hline Age at randomisation (years) & -0.56 & $<0.02$ \\
\hline Duration of diabetes (years) & $-0 \cdot 11$ & NS \\
\hline Bedtime (decimal 24 hour clock) & $-0 \cdot 68$ & $0 \cdot 002$ \\
\hline Tea-bed interval (hours) & $-0 \cdot 58$ & $<0 \cdot 01$ \\
\hline Insulin dose at randomisation (U/kg) & $-0 \cdot 04$ & NS \\
\hline $\begin{array}{l}\text { Glycosylated haemoglobin } \\
\text { at randomisation }(\%)\end{array}$ & -0.51 & $<0.05$ \\
\hline $\begin{array}{l}\text { Fasting blood glucose at randomisation } \\
(\mathrm{mmol} / \mathrm{l})\end{array}$ & $-0 \cdot 35$ & NS \\
\hline $\begin{array}{l}\text { Amount of short acting insulin on } \\
\text { regimen A (\% total daily dose) }\end{array}$ & -0.09 & NS \\
\hline
\end{tabular}

*Change in glycosylated haemoglobin=glycosylated haemoglobin value on regimen $A-$ value on regimen $B$.

ever, negative correlations with glycosylated haemoglobin at randomisation, age, the time of the bedtime injection, and the tea-bed interval. This suggests that the children who did better on regimen B had lower glycosylated haemoglobin values at randomisation, were younger, and went to bed earlier than those whose control deteriorated.

Parent questionnaire. Parents did not distinguish between the regimens on the grounds of blood glucose control or hypoglycaemia. The parents of 11 children viewed regimen $B$ as more convenient, and nine requested that their child continue on this regimen after completion of the trial.

\section{Discussion}

The exact aetiology of the dawn phenomenon remains unclear. Recent experience with continuous subcutaneous insulin infusion ${ }^{8}$ supports evidence from closed loop systems ${ }^{9}$ of the need for an increase in insulin delivery in the early hours of the morning. Discoveries of a similar phenomenon in non-insulin dependent diabetics ${ }^{10}$ and nondiabetics ${ }^{11}$ endorse the possibility of a circadian fluctuation of insulin metabolism ${ }^{12}$ or counter regulatory factors. ${ }^{13}$ Evidence for the existence of the dawn phenomenon is apparent in previous studies of conventional insulin regimens in childhood. ${ }^{14} 15$

While continuous subcutaneous insulin infusion is likely to reduce the magnitude of the dawn phenomenon, ${ }^{15}$ these devices are at present largely research tools and doubts remain about their safety $^{16}$ and particularly their acceptability in childhood. ${ }^{17}$

Most of our patients on twice daily insulin regimens have both injections within nine hours, and it would not be surprising if the smaller evening injection failed to suppress glycaemia for the remaining 15 hours. We therefore examined a more equally spaced regimen in younger children whose evenings are shorter, and whom we suspect to be more resistant to the three of four injection regimens advocated for older patients. ${ }^{18}$

The midmorning blood glucose peak produced by the dawn phenomenon proved impossible to assess directly in school aged children leading a normal life. Regimen B, however, produced significantly lower lunch time blood glucose concentration, which, coupled with the slightly lower values seen before breakfast, could be interpreted as attenuation of the dawn phenomenon. The lower blood glucose concentrations seen before the evening meal on regimen B probably reflect the higher dose of morning intermediate acting insulin (Table 2). The pronounced evening peak on regimen $B$ is a predictable consequence of omission of the evening short acting insulin. Overall glycaemic control, as measured by glycosylated haemoglobin, did not change, suggesting that this evening glycaemic peak on regimen B was balanced by lower blood glucose concentrations during the day.

The increase in mild hypoglycaemic episodes on regimen $B$ was not seen as a problem by parents. Many of these episodes occurred during the first month on the regimen, when parents responded to the higher bedtime blood glucose values by adding short acting insulin to the injection. Parental and child preference for regimen B was marked, and several families were reluctant to revert to regimen $A$ at the end of the study, despite acknowledging clear benefits to metabolic control.

Regimen B did not alter glycosylated haemoglobin over the group as a whole. Presumably the excess evening glycaemia on regimen $B$ balanced the 
higher morning glucose values seen on regimen A. It is possible, however, that greater changes in glycosylated haemoglobin might be observed in a less selected population.

If regimen $B$ were to reduce the dawn phenomenon, those subjects with the highest fasting blood glucose concentrations might be expected to benefit most. Our results do not support this. It is, however, difficult to correlate fasting with midmorning blood glucose values, and other factors-the morning dose of short acting insulin, the nature and quantity of carbohydrate consumed at breakfast, are likely to be equally important.

The strongest correlations with change in glycosylated haemoglobin were bedtime, tea-bed interval, and age. Age shows the weakest relation, but is likely to be most useful clinically. In this study seven of nine children below 8 years of age improved on regimen $\mathrm{B}$.

There are published reports concerning appropriate insulin regimens for children. Most authors suggest initial management with a single injection of intermediate acting insulin, with later introduction of morning short acting insulin and an evening injection as appropriate. ${ }^{141920}$ Regimens must, however, be tailored to individual needs, ${ }^{19}$ and age and duration of diabetes are likely to be important determinants.

We therefore believe that bedtime injections of intermediate acting insulin are a safe, convenient, and acceptable alternative to teatime injections for the younger child, and are likely to improve metabolic control in the under 8 year old child.

We thank Dr E J Hiller for allowing us to study patients under her care, Margaret Evans for blood glucose estimations, Dr J Ambler for performing glycosylated haemoglobin assays, Ian Hanning for $C$ peptide measurements, Sheila Nardi for typing the manuscript, and Dr Penny Standen for statistical advice. F R J Hinde is a Novo Research Fellow.

\section{References}

1 Tchobroutsky G. Relation of diabetic control to development of microvascular complications. Diabetologia 1978;15:143-52.

2 Malone JI, Hellrung JM, Malphus EW, Rosenbloom AL, Grgic A, Weber FT. Good diabetic control-a study in mass delusion. J Pediatr 1976;88:943-7.

${ }^{3}$ Schmidt MI, Hadji-Georgopoulos A, Rendell M, Margolis S, Kowarski $\mathrm{A}$. The dawn phenomenon, an early morning glucose rise; implications for diabetic intra-day blood glucose variation. Diabetes Care 1981;4:579-85.
${ }^{4}$ Nelson JD, Marliss EB, Albisser AM, Zinman B. Role of continuous component in subcutaneous 'open loop' insulin delivery. Lancet 1980;i:1383-6.

${ }^{5}$ Francis AJ, Home PD, Hanning I, Alberti KGMM, Tunbridge WMG. Intermediate acting insulin given at bed-time: effect on blood glucose concentrations before and after breakfast. $\mathrm{Br}$ Med J 1983;286:1173-6.

6 Ambler J, Janik B, Walker G. Measurement of glycosylated haemoglobin on cellulose acetate membranes by mobile affinity electrophoresis. Clin Chem 1983;29:340-3.

${ }^{7}$ Heding L. Radioimmunological determination of human C-peptide in serum. Diabetologia 1975;11:541-8.

${ }^{8}$ Geffner ME, Frank HJ, Kaplan SA, Lippe BM, Levin SR. Early morning hyperglycaemia in diabetic individuals treated with continuous subcutaneous insulin infusions. Diabetes Care 1983;6:135-9.

9 Clarke WL, Haymond MW, Santiago JV. Overnight basal insulin requirements in fasting insulin-dependent diabetics. Diabetes 1980;29:78-80.

10 Bolli GM, Gerich JE. The 'dawn phenomenon'-a common occurrence in both non insulin-dependent and insulindependent diabetes mellitus. $N$ Engl J Med 1984;310:746-50.

$"$ Schmidt MI, Lin QX, Gwynne JT, Jacobs S. Fasting early morning rise in peripheral insulin: evidence of the dawn phenomenon in non-diabetics. Diabetes Care 1984;7:32-5.

12 Skor DA, White NH, Thomas L, Santiago JV. Relative roles of insulin clearance and insulin sensitivity in the pre-breakfast increase in insulin requirements in insulin dependent diabetic patients. Diabetes 1984;33:60-3.

13 Nestler JE, Gebhart SSP, Blackard WG. Failure of a mid nocturnal insulin infusion to suppress the increased insulin need for breakfast in insulin-dependent diabetic patients. Diabetes 1984;33:266-70.

14 Werther GA, Jenkins PA, Turner RC, Baum JD, Twenty-four metabolic profiles in diabetic children receiving insulin injections once or twice daily. $\mathrm{Br}$ Med $J$ 1980;281:414-8.

15 Meschi F, Beccaria L, Vanini R, Szulc M, Chiumello G. Short term subcutaneous insulin infusion in diabetic children. Comparison with three daily insulin injections. Acta Diabetol Lat 1982;19:371-5.

16 Anonymous. Deaths in diabetics using insulin infusion pumps. Lancet 1982;i:636.

17 Knight G, Boulton AJM, Ward JD. Experience of CSII as an unsatisfactory tool in the management of diabetic teenagers. Diabetic Medicine 1984;1:142-3.

18 Schiffrin A. Treatment of insulin dependent diabetes with multiple subcutaneous insulin injections. Med Clin North Am 1982;66:1251-67.

19 Craig O. Childhood diabetes and its management. 2nd ed. London: Butterworth. 1981:46-7.

20 Dahlquist G, Blom L, Bolme P, et al. Metabolic control in 131 juvenile-onset diabetic patients as measured by HbAlc: relation to age, duration, C-peptide, insulin dose and one to two insulin injections. Diabetes Care 1982;5:399-403.

Correspondence to Dr F R J Hinde, Children's Department, University Hospital, Queen's Medical Centre, Nottingham NG7 2UH.

Received 31 December 1984 